\title{
PROPUESTA DE PERIODIZACIÓN Y DESARROLLO DEL SINDICALISMO EN COSTA RICA (1932-1998)
}

\section{PROPOSAL OF PERIODIZATION AND DEVELOPMENT OF TRADE UNIONISM IN COSTA RICA (1932-1998)}

\author{
José Andrés Díaz González*
}

\begin{abstract}
RESUMEN
Este artículo busca proponer un modelo de periodización y análisis del desarrollo del sindicalismo en Costa Rica durante el siglo XX. Para ello se busca identificar cómo los cambios políticos y económicos afectan a las organizaciones sindicales y cómo las han llevado a fragmentarse, a perder peso como organización social y a una disminución constante de la tasa de sindicalización; esto a pesar de mantener una base estable de sindicatos existentes en el país en las décadas finales del siglo pasado.
\end{abstract}

PALABRAS CLAVES: COSTA RICA * SINDICALISMO * HISTORIA * ORGANIZACIONES DE TRABAJADORES

\section{ABSTRACT}

This paper proposes a model of periodization and developmental analysis of trade unions in Costa Rica during 20th century. This seeks to identify as the political and economical changes influencing unionist organizations and how these have led to fragment, and loss of significance, as well as a constant unionization rate decrease, even though by the end of last century, a stable union base was still observed.

KEY WORDS: COSTA RICA $*$ TRADE UNIONISM $*$ HISTORY $*$ WORKERS' ORGANIZATIONS

Instituto de Estudios Sociales en Población (IDESPO) de la Universidad Nacional (UNA) y en la Escuela de Ciencias Políticas de la Universidad de Costa Rica (UCR).

jadg64@yahoo.com
$1 \quad$ El autor desea agradecer al Msc. Anthony Goebel Mc Dermott, Profesor de la Escuela de Historia de la Universidad de Costa Rica, los valiosos comentarios y observaciones realizados a una versión preliminar del presente texto. No obstante, cualquier error u omisión que el artículo presente es exclusivamente responsabilidad del autor. 
Los sindicatos como organizaciones sociales han jugado un papel crucial en la defensa de los trabajadores y en las luchas sociales en diferentes espacios geográficos e históricos. No obstante, su desarrollo está influenciado por una serie de circunstancias políticas, sociales y económicas, que afectan su capacidad de convocatoria y su fuerza para ejercer presión en las diferentes luchas sociales que han realizado a lo largo de la historia.

La historia del sindicalismo en Costa Rica es basta y compleja, es por ello que este trabajo pretende únicamente realizar un esbozo de periodización del desarrollo histórico de las organizaciones sindicales en el país, apoyado principalmente en el auge, descenso y estabilidad del número de sindicatos existentes en el país.
Debido a la complejidad ya mencionada, el modelo propuesto se fundamenta en dos factores principales: la situación económica y la situación política del país, y cómo afectan estas al desarrollo del sindicalismo (ver diagrama 1). De esta manera, se propone un modelo de cinco fases:

Génesis del sindicalismo (1890-1932)

Consolidación del sindicalismo (19321948)

Debilitamiento del sindicalismo (19481962)

Refortalecimiento del sindicalismo (1962-1980)

Decadencia del sindicalismo (19801998).

DIAGRAMA 1

MODELO DEL EXPLICATVO DEL DESARROLLO DEL SINDICALISMO EN COSTA RICA (1890-1998)

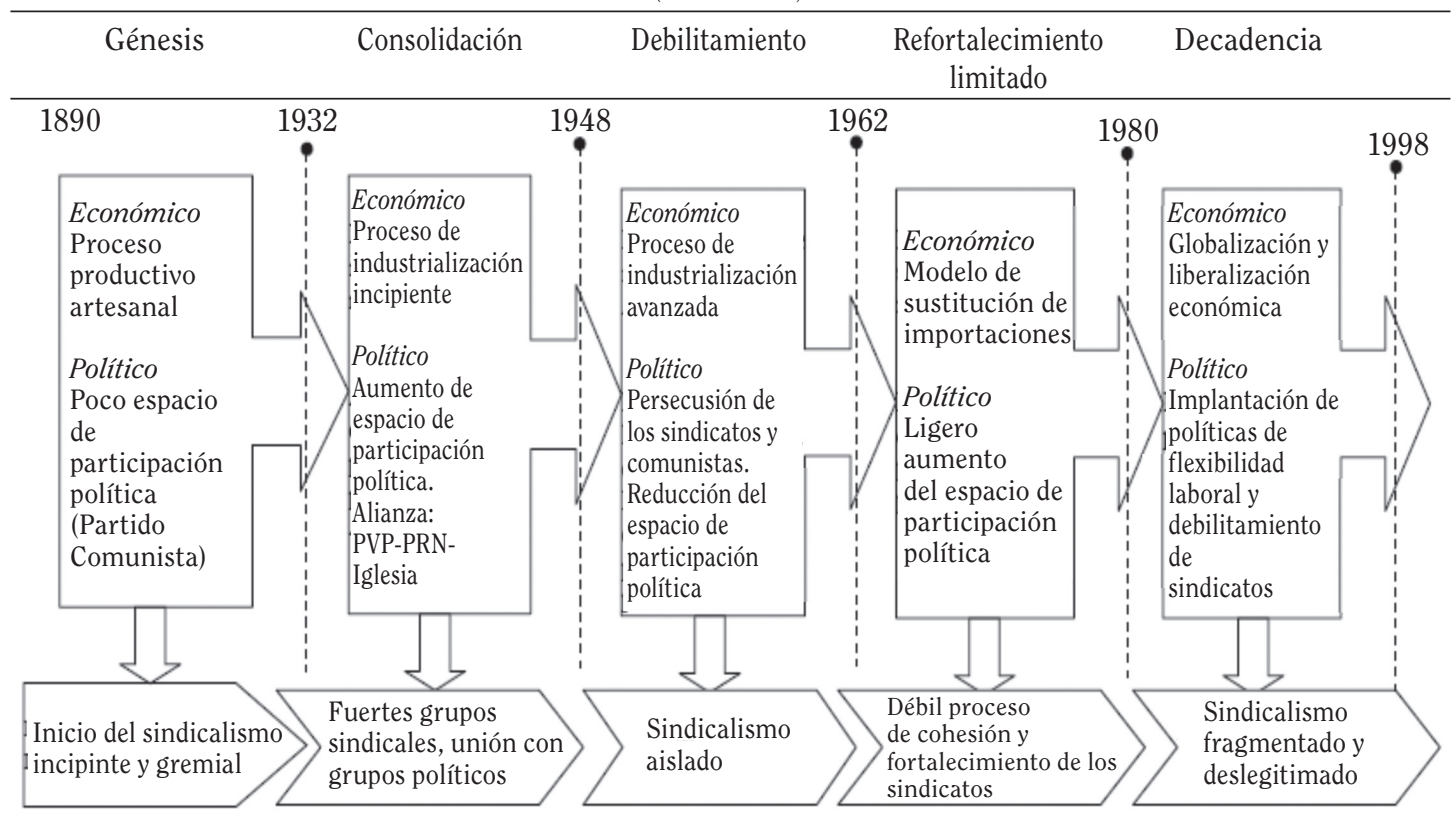

Fuente: Construcción propia. Noviembre, 2009.

Debido a las fuentes disponibles, el presente trabajo se concentra en las últimas cuatro etapas, sin embargo se realiza una somera introducción sobre la etapa considerada como génesis del sindicalismo en Costa Rica, la cual sirve como punto de partida para el desarrollo de la historia de estas organizaciones sociales.
Asimismo, se debe mencionar que por la naturaleza cuantitativa con la que se fundamenta la presente investigación, muchos factores de índole cualitativo, especialmente aquellos específicos del panorama social de cada una de las etapas identificadas, no han sido desarrollados con demasiada profundidad. Si bien esta es una de las debilidades del modelo 
propuesto, el mismo sigue considerándose válido, ya que lo que se pretende con el mismo es identificar $y$ analizar los ciclos de crecimiento $y$ decrecimiento de la población de organizaciones sindicales costarricenses, con el objeto de que sirva como punto de referencia a la hora de realizar investigaciones más detalladas sobre la dinámica social de este tipo de organizaciones sociales con su entorno.

Como limitación adicional hay que indicar que no fue posible obtener datos estadísticos referentes a los sindicatos costarricenses de 1971 $y$ hasta 1983. Este vacío cuantitativo fue recuperado revisando trabajos historiográficos sobre las organizaciones sindicales durante ese periodo, con los cuales se han podido estimar las líneas de comportamiento principales de las organizaciones sindicales durante el mismo, para así respaldar la propuesta de modelo de análisis realizada.

\section{GÉNESIS DE LAS ORGANIZACIONES SINDICALES: 1890-1932}

Las organizaciones sindicales nacen, según Bittel y Ramsey, como una protesta contra la situación adversa que se produce por la dualidad esquizoide que sufren los individuos al tratar de desempeñar su doble rol de ciudadano político y sujeto económico, que ocurre a finales del siglo XVIII y principios del siglo XIX².

Los individuos de esa época empezaban a desempeñar un rol de ciudadano político más activo mediante los procesos participativos de toma de decisiones, los cuales, si bien eran rudimentarios y muy incompletos, les brindaban una sensación de control sobre sus vidas. Paradójicamente, estos mismos individuos se encontraban sometidos a regímenes autocráticos en su rol de empleados ${ }^{3}$.

Así, las contradicciones existentes entre el papel político y económico dieron como resultado un rechazo final a la posición de "siervo" a la que todavía eran sometidos en el plano laboral. Los trabajadores empezaron a

2 Bittel, L. R. y Ramsey, J. E. Enciclopedia del Management. Vol. 3. $1^{\text {a }}$ Edición. Madrid: Editorial McGraw-Hill/Cetrum. 1988: 1110-1112. crear medios que les permitieran participar en las decisiones de su destino económico y laboral; estos mecanismos de participación recibieron el nombre de sindicatos ${ }^{4}$.

En lo que respecta a Costa Rica, gran cantidad de investigadores señalan que desde mediados $y$ finales del siglo XIX ya existe una pequeña clase obrera que empieza a tomar conciencia sobre la necesidad de un mejoramiento de sus condiciones socio-económicas. Estas manifestaciones ocurren principalmente en aquellas explotaciones en las cuales el capital extranjero estaba a cargo directamente del proceso de creación de valor, generalmente con la ayuda de fuerza de trabajo importada. Así, tenemos el ejemplo de la huelga de obreros italianos contratados para las obras de construcción del Ferrocarril al Atlántico en $1888^{5}$.

El historiador James Backer describe que esta etapa del desarrollo sindical en el país - comprendida aproximadamente entre 1854-1934- se caracteriza por un desarrollo incipiente $y$ lento $^{6}$. El hecho más importante de esta etapa viene a ser la Huelga General de 1920, convocada por la Confederación General de Trabajadores (CGT), la cual consigue que la jornada laboral quede establecida en ocho horas y se realice un aumento en los salarios de aproximadamente un $20 \%$.

Sin embargo, este mismo autor nos dice que ese movimiento pierde su identidad sindical cuando es absorbido por el Partido Reformista (PR) de Jorge Volio. Además, durante esta época la legislación laboral existente era de corte civilista y favorecía en poco o prácticamente nada al desarrollo del sindicalismo ${ }^{7}$.

$4 \quad$ Idem.

5 Rojas Bolaños, Manuel. "El desarrollo del Movimiento Obrero en Costa Rica; un intento de periodización". En: Abarca, Carlos A. y otros. Desarrollo del Movimiento Sindical en Costa Rica. $1^{\text {a }}$ Edición. San José. Editorial Universidad de Costa Rica, 1981: 13.

6 Regidor Umaña, Jorge Emilio. Las organizaciones sindicales centroamericanas como actores del sistema de relaciones laborales: el caso de Costa Rica. [PDF] San José. Oficina Internacional del Trabajo, 2003: 23.

$7 \quad$ Ibid. p. 24. 
Por su parte, el historiador costarricense Vladimir de la Cruz, señala que en Costa Rica la organización sindical tiene una larga trayectoria, que se inicia desde el último cuarto del siglo XIX, y que la transformación de la estructura productiva y social del país - a inicios del siglo Xx, en especial en el período que va de 1890 a 1912 - genera las condiciones para el surgimiento del sindicalismo propiamente dicho. Además, este historiador agrega que con la fundación del Partido Comunista (PC) -en 1931 - el sindicalismo experimenta un avance importante, tanto en la perspectiva organizativa, como en el contenido de sus luchas ${ }^{8}$.

\section{CONSOLIDACIÓN DEL SINDICALISMO: 1932-1948}

A partir de 1934 y hasta 1948 se da una consolidación de los sindicatos en Costa Rica. Una de las causas principales es la creación del PC el 16 de junio de 1931 por un grupo de intelectuales y obreros encabezados por Manuel Mora Valverde.

La presencia del PC significa un cambio importante en el carácter de las luchas obreras $y$ populares, pues estas empezaron a ser canalizadas orgánicamente, lo cual obliga a las élites a buscar respuestas concretas a las demandas planteadas, ante la posibilidad que el descontento adquiriera proporciones mayores ${ }^{9}$.

Es así, que durante toda la década de 1930 y hasta mediados de la década siguiente, el PC logra mantener una posición de hegemonía dentro del movimiento obrero costarricense. De esta forma, las luchas sociales más importantes acaecidas en esta época se dieron bajo su dirección, como la Gran Huelga Bananera de 1934, el movimiento obrero más significativo de este tipo realizado hasta entonces por la clase obrera nacional ${ }^{10}$.

8 De la Cruz, Vladimir. "Características y rasgos históricos del movimiento sindical en Costa Rica". En: Nowalski, Jorge (Editor). El sindicalismo frente al cambio: entre la pasividad y el protagonismo. $1^{\text {a }}$ Edición. San José. Editorial DEI, 1997: 17.
Otro factor que propicia la expansión del movimiento sindical durante esta época fue el ascenso experimentado por los sectores obreros en el seno de la clase trabajadora; ya que esto hizo posible que los intereses de este sector comenzaran a predominar en el interior de la lucha sindical ${ }^{11}$.

A este fenómeno, la historiadora Marielos Aguilar señala que deben sumársele algunos elementos coyunturales que propiciaron el crecimiento de las organizaciones sindicales, estos son: la elección del Dr. Rafael Ángel Calderón Guardia como Presidente de la República en 1940 y el ascenso de Monseñor Sanabria como Jefe principal de la Iglesia Católica Costarricense ${ }^{12}$.

Las medidas reformistas representadas en estos personajes, permite que se dé una singular alianza entre el Gobierno, la Iglesia Católica y el PC a partir de 1942; alianza de la cual surgieron las Garantías Sociales y el Código de Trabajo; medidas que brindaron al movimiento sindical el espacio social y jurídico necesario para su fortalecimiento y expansión ${ }^{13}$. Así, podemos ver en el Cuadro 1, como se genera un aumento vertiginoso de sindicatos existentes entre 1943 y 1944, y en los años siguientes se continúan inscribiendo nuevos sindicatos. Esto indica el ambiente favorable que reinaba en el país para las organizaciones sindicales.

Esta estrecha relación entre los sindicatos - representados políticamente por el PC-y el gobierno desemboca en que el 13 de junio de 1943 fuera disuelto el PC y en su lugar naciera el Partido Vanguardia Popular (PVP).

11 Aguilar H., Marielos. Clase trabajadora y organización sindical en Costa Rica 1943-1971. 1. Edición. San José: Editorial PORVENIR-FLACSOICES, 1989. p.19.

$12 \quad$ Ibid. p. 20.

13 Idem. 
CUADRO 1

SINDICATOS INSCRITOS Y DISUELTOS EN COSTA RICA (1943-1948)

\begin{tabular}{cccc}
\hline AÑO & INSCRITOS & DISUELTOS & VIGENTES \\
\hline 1943 & 85 & & 85 \\
1944 & 115 & & 200 \\
1945 & 25 & 22 & 203 \\
1946 & 18 & 8 & 213 \\
1947 & 18 & 31 & 200 \\
1948 & 15 & 11 & 204 \\
\hline
\end{tabular}

Fuente: Anuario Estadístico. Dirección General de Censos. 1971, p. 212. Citado por: Aguilar H., Marielos. Clase trabajadora y organización sindical en Costa Rica 1943-1971. 1. a Edición. San José: Editorial PORVENIR-FLACSO-ICES, 1989. p. 21; Capítulo I, Cuadro 3.

Este nuevo partido político defiende un programa más moderado de transformaciones económicas y sociales, el cual apoyaba abiertamente la política social del Presidente Calderón Guardia, pues consideraba que no era contradictorio con sus principios ${ }^{14}$.

Esta alianza incluso propicia que el 22 de septiembre de ese mismo año, se creara la coalición Bloque de la Victoria, conformada por el PVP y el Partido Republicano Nacional (PRN), para enfrentar juntos así las elecciones presidenciales de $1944^{15}$.

Las elecciones de 1944 se llevaron a cabo dentro de un ambiente de irregularidades, $y$ aunque los resultados fueron favorables para el Bloque de la Victoria, este solo obtuvo el 66\% de los votos emitidos - sin contabilizar los posibles fraudes-; en contraste de lo ocurrido en 1940, donde el PRN y el PC habían obtenido

14 Rojas Bolaños, Manuel. Op. Cit. p.22.

15 Idem. de forma conjunta el 95\% de los votos emitidos. De esta forma se puede vislumbrar el inicio del proceso de polarización política en Costa Rica $^{16}$. Por lo tanto, aunque los comunistas no abandonan la organización sindical ni la lucha por mejoras inmediatas en las condiciones de trabajo y de vida de los obreros; es indudable que la alianza producida entre estos $y$ algunos sectores de la burguesía nacional modifica de forma sustancial la forma en que se conducen las luchas obreras después de $1942^{17}$. 
Otro aspecto a considerar es la promoción de un sindicalismo de corte católico que ocurre en este periodo; y el cual inicia en 1942 con la fundación de la Juventud Obrero Católica, cuyo objetivo era la formación de dirigentes sindicales, $y$ toma mayor fuerza en 1943 con la fundación de la Central Sindical Costarricense Rerum Novarum. La intención de la Iglesia Católica fue buscar su influencia en las organizaciones sindicales, estaba claramente orientada en no dejar este grupo social en control únicamente de los grupos de izquierda, $y$ de esta manera buscaba aumentar su base social $^{18}$.

El gráfico 1 muestra como durante este periodo es claro que las organizaciones sindicales toman fuerza, con un fuerte crecimiento entre 1943 a 1944, y a continuación se presenta una estabilidad en los cambios de la población de las organizaciones sindicales, tal y como lo muestra el cambio porcentual también representado en dicho gráfico.

Lo anterior es indicador de la estabilidad ya mencionada, esto debido a que son pocos los sindicatos que desaparecen en este periodo $y$ pocos los sindicatos nuevos que surgen.

\section{DEBILITAMIENTO DEL MOVIMIENTO \\ SINDICALISTA: 1948-1962}

La catarsis para el sindicalismo en Costa Rica viene con la Revolución de 1948 y la victoria del Ejército de Liberación Nacional, comandado por José Figueres Ferrer. Esta tercera etapa, que comprende el período de 1948 a 1962, se caracterizó principalmente por una serie de medidas que debilitan directamente la fuerza del movimiento sindicalista en Costa Rica, entre ellos la proscripción del PVP, por medio del decreto 105, el cual establece que:

Se prohíbe la organización o funcionamiento de partidos políticos que por su programa, medios de acción, vinculaciones internacionales o antecedentes, se opongan al régimen de gobierno representativo y democrático de la República,

\section{GRÁFICO 1 \\ CAMBIOS EN LA POBLACIÓN DE SINDICATOS DE COSTA RICA (1943-1948)}

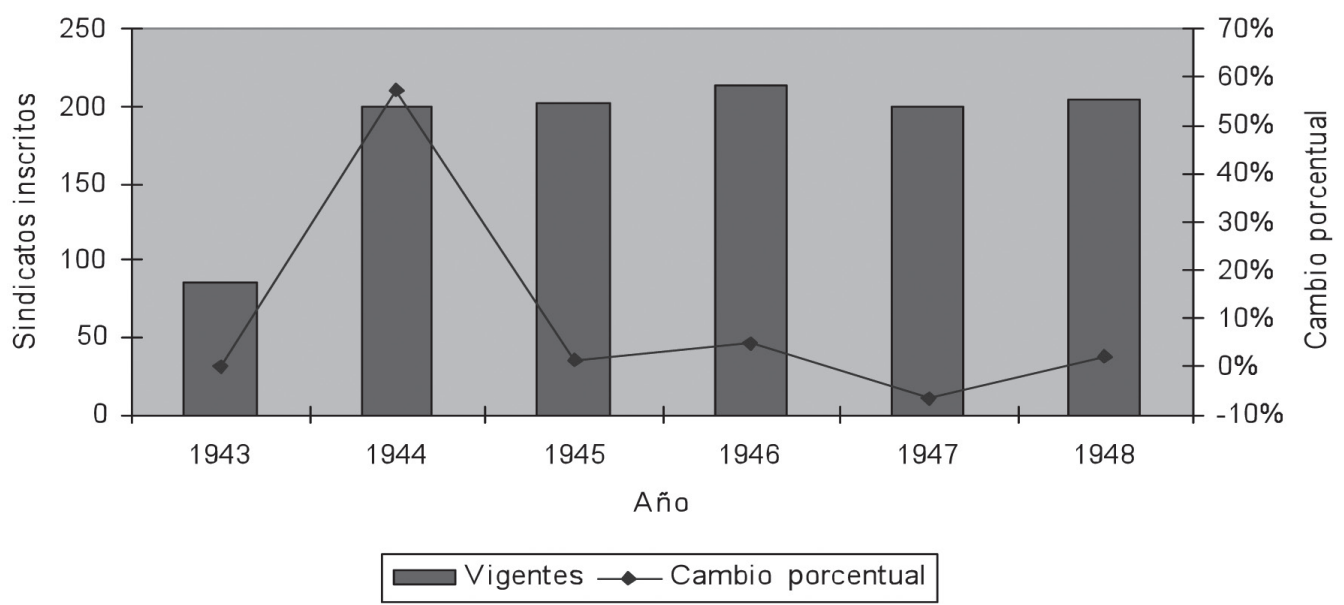

Fuente: Construcción propia, a partir de los datos encontrados en: Ministerio de Trabajo y Seguridad. Base de datos electrónica: listado de Sindicatos. [XLS]. Oficina de Organizaciones Sociales. Noviembre, 2009.

18 Molina Jiménez, Iván. Anticomunismo reformista: competencia electoral y cuestión social en Costa Rica (1931-1948). 1. a Edición. San José: Editorial Costa Rica, 2009. Pp. 159-171. 
o que atenten contra la soberanía nacional [...] Declárase comprendido expresamente en la prohibición del artículo primero al Partido Vanguardia Popular ${ }^{19}$.

Además, la Junta de Gobierno — presidida por Figueres Ferrer - emite otros decretos más específicos en contra de los trabajadores que habían brindado su apoyo a los gobiernos anteriores. Así, en julio de 1948 se crea el Tribunal de Ética para funcionarios de la Docencia, como una medida represiva contra los maestros que habían apoyado al PRN y al PVP20.

También aprobó otro decreto que autorizaba al Gobierno a despedir a todos los funcionarios públicos que fueran simpatizantes del PVP, sin responsabilidad patronal. Este decreto se hacía extensivo a los patronos de empresas privadas, quienes quedaban autorizados a despedir a aquellos trabajadores que consideraran "peligrosos" por sus ideales o su militancia política $^{21}$.

19 Archivos Asamblea Legislativa de Costa Rica. Colección de Leyes y Decretos. II semestre de 1948. pp.16-18. Citado por: Aguilar H., Marielos. Op. Cit. p.72.

20 Aguilar H., Marielos. Op. Cit. p.72.

$21 \quad$ Idem.

Los sectores vencedores de la Guerra Civil del 48 se apropiaron así de la bandera del "anticomunismo"; bajo la consigna de la cual fueron perseguidos la mayoría de las organizaciones sindicales del país. De esta forma, en junio de 1949 el Ministro de Trabajo, Padre Benjamín Núñez Vargas - creador junto al Arzobispo de San José de la Confederación de Trabajadores Rerum Novarum (CTRN) - solicita la disolución judicial de la Confederación de Trabajadores de Costa Rica (CTCR), principal apoyo y partidario activo del PVP22.

La disolución de la CTCR afecta drásticamente a los sindicatos pertenecientes a esta organización, llevándolos a una acelerada desaparición, al punto que entre 1948 y 1953 aproximadamente el $64 \%$ de los sindicatos costarricenses habían desaparecido (ver Cuadro 2).

Aún así y gracias a los esfuerzos de los dirigentes sindicales, la estructura sindical pudo ser levantada. De esta forma, en marzo de 1953 se funda una nueva central obrera que vendría a sustituir a CTCR, la Confederación General de Trabajadores Costarricenses (CGTC); pero a pesar de esto, las condiciones políticas y sociales del país son adversas para la constitución de movimientos obreros independientes ${ }^{23}$.

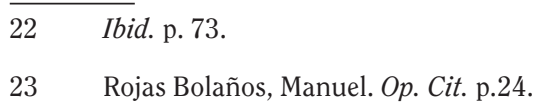

CUADRO 2

SINDICATOS INSCRITOS Y DISUELTOS EN COSTA RICA (1948-1953)

\begin{tabular}{cccc}
\hline AÑO & INSCRITOS & DISUELTOS & VIGENTES \\
\hline 1948 & 15 & 11 & 204 \\
1949 & 11 & 51 & 164 \\
1950 & 14 & 1 & 177 \\
1951 & 11 & 12 & 176 \\
1952 & 13 & --- & 189 \\
1953 & 16 & 131 & 74 \\
\hline
\end{tabular}

Fuente: Dirección General de Censos. Anuario Estadístico. 1971, p. 212. Citado por: Aguilar H., Marielos. Clase trabajadora y organización sindical en Costa Rica 1943-1971. 1. ㄹ Edición. San José: Editorial PORVENIR-FLACSO-ICES, 1989. p. 75; Capítulo III, Cuadro 2. 
Sin embargo, en la década de 1950 se inicia el proceso de industrialización de Costa Rica. Esto provoca cambios importantes en la distribución de la población económicamente activa del país; ocasionando que entre 1950 y 1963 el sector secundario aumentara del 15,9\% al $18,4 \%$ y el sector de servicios pasara del
$29,1 \%$ al $32,1 \%{ }^{24}$. Este crecimiento favoreció la constitución de sindicatos dentro de las instituciones del Estado (ver Cuadro 3), lo cual indujo que el número de sindicatos existentes en la parte final de la década de 1950 casi alcanzara al número de sindicatos existentes antes de la Guerra Civil de 1948.

CUADRO 3

SINDICATOS INSCRITOS Y DISUELTOS EN COSTA RICA (1954-1959)

\begin{tabular}{cccc}
\hline AÑO & INSCRITOS & DISUELTOS & VIGENTES \\
\hline 1954 & 35 & --- & 109 \\
1955 & 14 & --- & 123 \\
1956 & 18 & --- & 141 \\
1957 & 16 & --- & 157 \\
1958 & 28 & --- & 185 \\
1959 & 14 & --- & 199 \\
\hline
\end{tabular}

Fuente: Dirección General de Censos. Anuario Estadístico. 1971, p. 212. Citado por: Aguilar H., Marielos. Clase trabajadora y organización sindical en Costa Rica 1943-1971. 1. ㄹ Edición. San José: Editorial PORVENIR-FLACSO-ICES, 1989. p. 115; Capítulo IV, Cuadro 2.

Otro elemento importante es el inicio de las luchas por la firma de convenciones colectivas, ya que aunque estas se habían incluido desde 1943 en el Código de Trabajo, no es sino hasta 1950 que los sindicatos comenzaron a hacer uso de ese derecho.

Los primeros en firmar una Convención Colectiva fueron los trabajadores de artes gráficas en septiembre de 1950 seguidos por los zapateros, los sastres, los panaderos y los trabajadores de la madera ${ }^{25}$. Las peticiones reunidas en estas convenciones colectivas no iban más allá de las peticiones que tradicionalmente habían clamado los sindicatos costarricenses, aún en coyunturas más favorables para su labor organizativa: aumentos salariales, reducción de jornadas laborales, pagos de días feriados, reformas a los reglamentos internos de trabajo, entre otros, eran las demandas más comunes solicitadas por medio de las Convenciones Colectivas ${ }^{26}$.

Pero una característica que no permite a los sindicatos recuperar su fortaleza de antaño por medio del uso de las Convenciones Colectivas, se debe a que estas fueron un fenómeno casi exclusivamente urbano, $y$ no llegaron a adoptarse con la fuerza suficiente entre los trabajadores agrarios; lo cual redujo drásticamente el marco de acción con el que contaban los sindicatos, produciendo así un nuevo descenso en las fuerzas que aparentemente estaban recobrando ${ }^{27}$.
$24 \quad$ Ibid. p. 25.
$26 \quad$ Ibid. p. 97.

$27 \quad$ Idem 
Las organizaciones sindicales se ven igualmente perjudicadas por la falta de garantía para su normal funcionamiento. La principal arma con la que cuentan los patrones para combatir cualquier acción sindical, es su derecho de despedir a sus trabajadores — con o sin justa causa - con el pago de las prestaciones estipuladas en la legislación laboral. De esta forma, a partir del momento en que se iniciaba la tramitación de alguna Convención Colectiva, los patronos se las arreglan para despedir a la mayoría de los trabajadores que han firmado el pliego de peticiones.
El gráfico 2 nos muestra como durante este periodo la volatilidad de las organizaciones sindicales existentes en el país fue mucho mayor, especialmente entre 1954 y 1958. Esto indica poca estabilidad en el número de sindicatos vigentes, así como una alta tasa de sindicatos nuevos y altas posibilidades de que estos desaparezcan, lo cual implica que tenían poca capacidad de consolidarse $y$ adquirir fuerza para presentarse como una opción representativa legítima ante la población trabajadora.

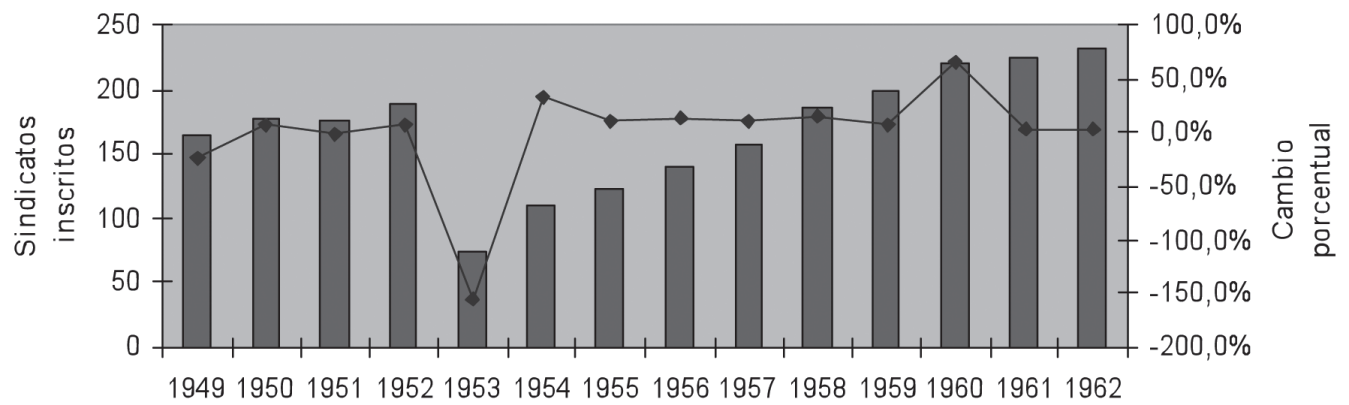

Año

Vigentes $\multimap$ Cambio porcentual

Fuente: Construcción propia, a partir de los datos encontrados en: Ministerio de Trabajo y Seguridad. Base de Datos electrónica: listado de Sindicatos. [XLS]. Oficina de Organizaciones Sociales. Noviembre, 2009.

En cuanto a las luchas sindicales, estas organizaciones se enfrascan durante la década de 1950 — y continúan en la década de 1960_ en la defensa de reivindicaciones elementales, tales como salarios, jornadas laborales, atención médica, mejoras a la vivienda, etc., sin avanzar más allá de estos límites; esto a pesar de que el contexto económico, social y político que enmarca a la acción sindical, sí sufre cambios transcendentes ${ }^{28}$.

28 Aguilar Hernández, María de los Ángeles. "Clase trabajadora y organización Sindical en Costa Rica (1948-1971)". [Tesis para optar por el Grado de
De esta forma, durante todo este periodo los sindicatos costarricenses encuentran serios obstáculos para su organización; sumado estos a su exclusión casi total del escenario político debido a la desaparición del PVP y a la persecución a la que fueron sometidos sus miembros, podemos concluir que la lucha del movimiento obrero nacional se ve prácticamente paralizada, lo que le impide alcanzar algún logro significativo.

Magíster en Scientae en Sociología] Universidad de Costa Rica. San José, 1987. p. 236. 


\section{REFORTALECIMIENTO DEL SINDICALISMO:} 1962-1980

Con la firma del Tratado Multilateral de Libre Comercio e Integración Económica por los países centroamericanos, y la entrada en funcionamiento del Mercado Común Centroamericano (MCC), se acelera el desarrollo industrial del país —un desarrollo industrial sustitutivo - el cual pasa a representar más del $15 \%$ del PIB. Pero el sector agrícola permanece como el más importante $y$, en particular, como el gran proveedor de divisas para financiar al sector industrial ${ }^{29}$.

29 Córdoba Arancibia, Juan. "La Integración Centroamericana y los trabajadores". Portella de Castro, María Silvia y Wachendorfer, Achim
Este crecimiento industrial promueve la creación de organizaciones sindicales (ver Cuadro 4), las cuales entre 1960-1971 aumenta su número en un poco más de un $50 \%$. Por lo tanto, podemos ver que este periodo - aproximadamente de 1962 a1980 - se caracteriza por un aumento del número de sindicatos activos en Costa Rica.

(Coordinadores). Sindicalismo y globalización: la dolorosa inserción en un mundo incierto. $1 .^{a}$ edición. Caracas: Editorial Nueva Sociedad, 1998. p. 89 .

CUADRO 4

SINDICATOS INSCRITOS Y DISUELTOS EN COSTA RICA (1960-1971)

\begin{tabular}{cccc}
\hline AÑO & INSCRITOS & DISUELTOS & VIGENTES \\
\hline 1960 & 22 & 1 & 220 \\
1961 & 4 & --- & 224 \\
1962 & 9 & 1 & 232 \\
1963 & 16 & --- & 248 \\
1964 & 22 & 2 & 268 \\
1965 & 178 & 86 & 360 \\
1966 & 19 & 163 & 216 \\
1967 & 26 & 20 & 222 \\
1968 & 28 & --- & 250 \\
1969 & 25 & 4 & 271 \\
1970 & 31 & -- & 302 \\
1971 & 31 & --- & 333 \\
\hline
\end{tabular}

Fuente: Dirección General de Censos. Anuario Estadístico. 1971, p. 212. Citado por: Aguilar H., Marielos. Clase trabajadora y organización sindical en Costa Rica 1943-1971. 1. a edición. San José: Editorial PORVENIR-FLACSO-ICES, 1989. p. 151. Capítulo V, cuadro 1. 
Además, en este periodo se da una fuerte unidad dentro del movimiento sindical costarricense en busca del fuero sindical. La CGTC estuvo siempre en la búsqueda de esa unidad sindical, el Frente o Federación de Obreros y Campesinos Cristianos (FOCC) estuvo también dispuesto, y en 1965, la CGTC, la CCTRN y el FOCC hacen una manifestación tendiente a lograr el fuero sindical ${ }^{30}$.

Como se señala anteriormente, el sector económico más importante continua siendo el agrícola, lo cual repercute en que el mayor número de organizaciones sindicales registradas durante esos años fueran de índole agrícola, seguidas por el sector servicios y la industria manufacturera $^{31}$.

Durante toda la década de 1960 , la política sindical del Estado costarricense no sufre mayores cambios. Su actitud de indiferencia hacia las organizaciones sindicales continúa siendo la nota predominante, independientemente de que si los dirigentes del Gobierno provienen del Partido Liberación Nacional (PLN) o de la oposición ${ }^{32}$.

La disminución de la capacidad de respuesta de la clase trabajadora para defenderse del maltrato y de la explotación patronal, fue celebrada por Mario Echandi, quien al dejar la Presidencia de la República en 1962 manifiesta:

Podemos dirigir nuestra mirada, tranquilos, a todos los rumbos del suelo patrio - aún aquellos donde hubo antes agitación y violencia- para apreciar el magnifico espectáculo de un país donde la ennoblecedora actividad del trabajo se desenvuelve en un ambiente de confraternidad, armonía y mutua comprensión ${ }^{33}$.

Pero para la década de 1970 el desarrollo del sindicalismo en Costa Rica se encuentra nuevamente en auge, gracias al acelerado cre-

\footnotetext{
30 Regidor Umaña, Jorge Emilio. Op. Cit. p. 29.

31 Aguilar H., Marielos. Op. Cit. p. 152.

$32 \quad$ Ibid. p. 172.

$33 \quad$ Ibid. p.173.
}

cimiento capitalista que había tenido el país en los últimos 18 años $^{34}$. Durante esta época, a las luchas realizadas por el movimiento sindical se une el movimiento estudiantil, lo cual favorece a la radicalización de sectores importantes de la juventud universitaria, los cuales pasan a engrosar las filas de los partidos de izquierda -quiénes dejan de estar proscritos a partir de 1975-, y el movimiento de los campesinos sin tierra $^{35}$. Todo eso repercute aún más en el fortalecimiento de las organizaciones sindicales.

También durante esta época el sindicalismo —en el sector público - adquiere una dimensión y posición importante, y pasa a constituir la membresía mayoritaria del movimiento sindical, la cual, aunque se ha debilitado, se mantiene hasta la fecha ${ }^{36}$. Así se fortalece el movimiento sindical en sectores como el energético, telecomunicaciones, educación, salud; pero también surgen grandes competencias entre los partidos tradicionales $y$ de izquierda por controlarlos, en el primer caso, los grupos socialdemócratas pregonando la alianza del Estado con el sindicalismo del sector público y, en el segundo, para orientarlos según sus criterios ideológicos y doctrinarios, de tal manera que el reaparecido PVP, el Movimiento Revolucionario del Pueblo (MRP), el Partido Socialista (PS), el Partido Revolucionario de los Trabajadores (PRT), La Hormiga Negra y la Hormiga Roja, forcejean para que se elijan en las directivas sindicales dirigentes ligados a sus movimientos ${ }^{37}$.

Si bien es cierto que en este periodo se enriquece la membresía sindical, la verdad es que se dan ciertas características que lo convierten en un movimiento atomizado $y$ fragmentado. Esto se debe a varios factores:

La influencia de las corrientes sindicales de corte internacional, los sentimientos y manifestaciones absolutamente gremialistas o elitistas, así como las posiciones

\footnotetext{
34 Rojas Bolaños, Manuel. Op. Cit. p. 27.

$35 \quad$ Idem.

36 Regidor Umaña, Jorge Emilio. Op. Cit. p. 30.

$37 \quad$ Idem.
} 
hegemónicas o sectarias y en algunos casos ideológicas o caracterológicas [sic], separaron al movimiento sindical ${ }^{38}$.

Efectivamente, este fenómeno - aunado a una cultura individualista-, lejos de constituir sindicatos por rama de producción, o por sectores de la economía, opta por el sindicalismo gremial o de empresa, de tal suerte que la atomización en algunas instituciones fue de

38 Aguilar Arce, Rodrigo. Actualidad del movimiento sindical en Costa Rica. 1. a edición. San José: Sindicatos de Educadores CostarricensesFundación Friedrich Ebert, FES. 1993. p.20. grandes proporciones. Tal es el caso de la Caja Costarricense del Seguro Social, donde se han llegado a integrar hasta 36 sindicatos $^{39}$.

En cuanto al gráfico 3, este nos permite apreciar que si bien todavía hay una cierta inestabilidad en la población de organizaciones sindicales durante esta época, es posible observar como empieza a notarse una leve pero estable recuperación de los sindicatos en el país.

$39 \quad$ Oficina de Organizaciones Sociales. Base de datos electrónica: listado de sindicatos. [XLS]. Ministerio de Trabajo y Seguridad. Proporcionado el 19 de junio, 2006.

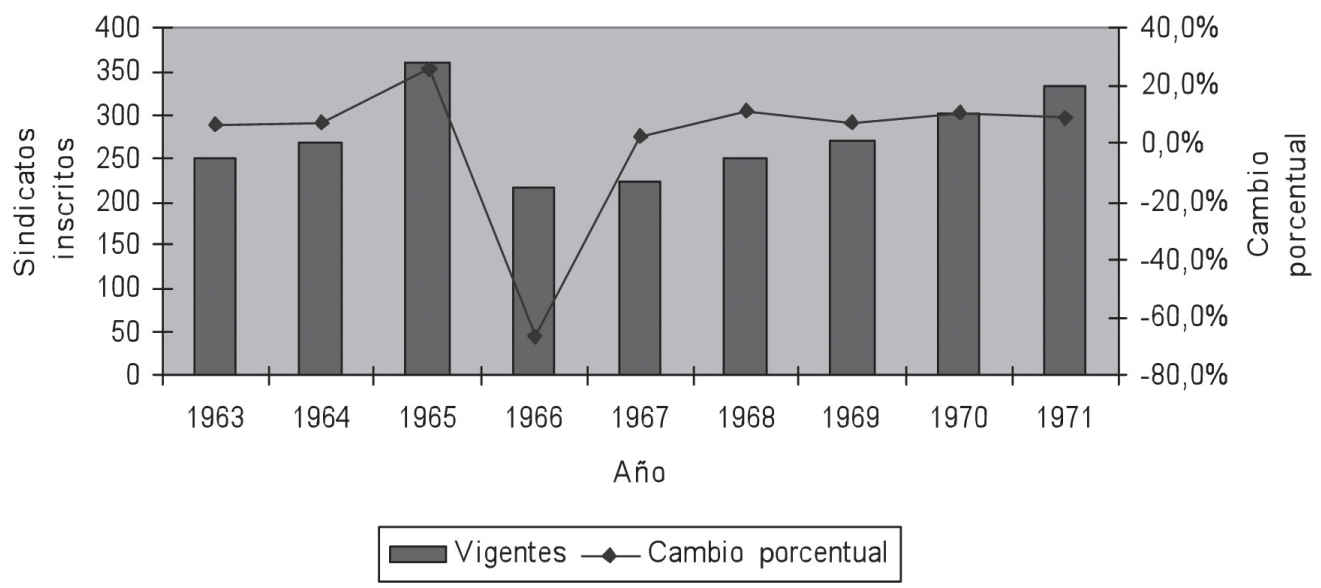

Fuente: Construcción propia, a partir de los datos encontrados en: Ministerio de Trabajo y Seguridad. Base de Datos electrónica: listado de Sindicatos. [XLS]. Oficina de Organizaciones Sociales. Noviembre, 2009. 
No obstante, la década de 1970 también marca el inicio de una crisis económica que afecta a todos los países centroamericanos, incluyendo a Costa Rica; que ocasiona la desaparición del MCC. Durante los años de la integración económica centroamericana, no se llevaron a cabo transformaciones estructurales al nivel económico y social que impidieran que los beneficios del crecimiento, en el contexto de esta lleguen a las mayorías. Por el contrario, es incluso posible que la desigualdad de la distribución de la riqueza y el ingreso haya crecido ${ }^{40}$.

Si sumamos a este hecho, los problemas de disponibilidad de divisas para la industrialización sustitutiva $y$, con ello, para la integración; sumado al aumento de la deuda externa durante los años 70 , se puede fácilmente argumentar que la crisis económica vivida durante la década de 1980 - la cual afecta tanto al campo social como político del país- es ocasionada por el mismo proceso de la integración centroamericana ${ }^{41}$.

\section{DESARROLLO DE LA TESIS NEOLIBERAL Y DECADENCIA DEL SINDICALISMO: 1980-1998}

Se puede remontar a la década de los 80 como el punto histórico que marca el inicio de una serie de medidas económicas de corte neoliberal que vienen a reducir el espacio de acción de los sindicatos. En esta década se manifiesta con fuerza una seria crisis político-económica en Centroamérica, estimulada en su aspecto económico por el fracaso del MCC y en lo político por el surgimiento de conflictos armados que afectaron a los países centroamericanos - con excepción de Costa Rica-y que ocasionaron la inestabilidad de los sistemas políticos del área, así como el inicio del declive de las organizaciones sindicales en Costa Rica ${ }^{42}$.

\footnotetext{
$40 \quad$ Córdoba Arancibia, Juan. Op. Cit. p. 91.

$41 \quad$ Ibid. p. 92.
}

42 Proyecto Estado de la Nación en Desarrollo Humano Sostenible. Informe de la Auditoría Ciudadana sobre la calidad de la Democracia. 1. ${ }^{a}$ edición. San José: Proyecto Estado de la Nación, 2001. p. 32.
Con la venida de la crisis de los 80 , los gobiernos centroamericanos adoptan como "salvavidas" las soluciones "estimuladas" por el gobierno de los Estados Unidos (EEUU) por medio de organismos internacionales como la Agencia Internacional de Desarrollo (AID), el Banco Mundial (BM) y el Fondo Monetario Internacional (FMI); lo cual los lleva a tener un comportamiento unilateral y aislacionista que excluía toda posibilidad de acción conjunta tanto entre los países centroamericanos, como entre los gobiernos y los diferentes movimientos sociales ${ }^{43}$.

Así, la ideología dominante en los gobiernos a partir de esa época es que la inversión económica internacional eficiente es la base para la solución de todos los problemas económicos y esta, a su vez, es la vía hacia la resolución de los problemas sociales ${ }^{44}$.

Este elemento marca el inicio del predominio del neoliberalismo en las políticas gubernamentales que ocasionan una serie de medidas políticas, como la promoción del solidarismo y la aparición de listados de nombres de los activistas sindicales, que viene a repercutir en el debilitamiento $y$ fragmentación del sindicalismo ${ }^{45}$.

Acerca del solidarismo, Víctor Rojas Morales considera que este ha sido:

... la opción favorita de los patronos para combatir al sindicalismo, para lo cual han contado con el apoyo de la Iglesia Católica, la cual, a través de la Escuela Social Juan XXIII, se ha encargado con gran energía de su promoción. Además, los solidaristas lograron influir en los trabajadores afiliados a sindicatos de la CUT $y$ ante el desconcierto y el desencanto sufrido por los sindicatos, los traba-

\footnotetext{
43 Arancibia Córdobez, Juan. Op. Cit. p. 92.

44 Ibid. p. 94.

45 Romano Schutte, Giorgio. "El sindicalismo bananero en América Central en busca de nuevos caminos". Portella de Castro, María Silvia y Wachendorfer, Achim (Coordinadores). Sindicalismo y globalización: la dolorosa inser-

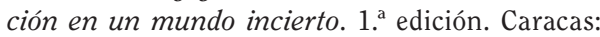
Editorial Nueva Sociedad, 1998. p. 275.
} 
jadores optaron por abrazar una alternativa que parecía más clara, fuerte $y$ beneficiosa ${ }^{46}$.

Estas medidas suponen una crítica al modelo de desarrollo seguido por el país en las dos décadas anteriores, generando, las condiciones de la transformación del sistema de relaciones laborales que estaba vigente desde la promulgación del Código de Trabajo en 1943. Una vez posicionado un sector político neoliberal en ambos Partidos Políticos mayoritarios —el PLN y el Partido Unidad Social Cristiana (PUSC) - se producen cambios en la estructura de contratación del Estado tendientes a reducirlo, lo que provoca una disminución de la membresía sindical, no porque la ataque directamente, sino como un efecto de la misma reestructuración de las relaciones laborales desde la óptica neoliberal ${ }^{47}$.

Paralelo a ello se produce una situación difícil a raíz de los acontecimientos que sufren los partidos de izquierda, lo que provoca una mayor fragmentación del movimiento sindical, donde el esfuerzo que habían realizado la CGT $y$ la Federación Nacional de Trabajadores del Sector Público (FENATRAP) para constituir la Confederación Unitaria de Trabajadores (CUT), quedan en el olvido al producirse una escisión en la CUT y surgir de esa manera la CTCR. Esto con el agravante que muchos de los sindicatos se declaran independientes - no federados ni confederados- $y$, posteriormente, los problemas sucedidos en PVP hacen que muchos de los sindicatos que habían quedado en la CUT se separen de ella y también se declaren independientes. Por otra parte, en ese período también la Confederación Costarricense de Trabajadores Democráticos (CCTD) vuelve a sufrir una nueva escisión surgiendo la Confederación Nacional de Trabajadores (CNT), que también se afilia a CIOSL-ORIT ${ }^{48}$.

46 Rojas Morales, Víctor. "Crisis y movimiento sindical en Costa Rica (1980-1985)". [Tesis para optar por el Grado de Licenciado en Historia] Universidad de Costa Rica. Facultad de Ciencias Sociales. San José, 1999. p. 142.

Regidor Umaña, Jorge Emilio. Op. Cit. p. 32.
Ante el panorama sindical de desarticulación, división y aislamiento, nuevamente emergen intentos de las confederaciones y algunos sindicatos no confederados de articular esfuerzos y fijar agendas comunes para enfrentar la agresión a la que se les somete. A principios de la década de los 80 emerge el Frente Democrático de los Trabajadores (FDT), que aglutina a una serie de centrales, federaciones $y$ sindicatos no confederados y que, precisamente en 1982, logra realizar una multitudinaria movilización hacia la Asamblea Legislativa para exigir una reforma a la Ley Orgánica del Banco Central para monopolizar el comercio del dólar ${ }^{49}$.

Después de esa acción, el FDT coordina nuevas acciones de movilización con la CUT. Por causas más de carácter hegemónico que de otra naturaleza ese frente desaparece, $y$ no es sino hasta 1985 que se inicia un nuevo intento de articulación al crearse la Coordinadora Patriótica de Organizaciones Sindicales (CPOS), que también llega a perder su potencial. A finales de la década del 80 nuevamente se da un importante esfuerzo al crearse el Consejo Permanente de Trabajadores (СРT), al cual no solo ingresan sindicatos, sino que se abre al movimiento cooperativo y al comunal ${ }^{50}$.

En resumen, según Arnoldo Mendoza Mora, tres son las causas que provocan que el sindicalismo costarricense entre en crisis durante la década de 1980. La primera es la desaparición del movimiento sindical del escenario político nacional, esto ocurrido por múltiples conflictos internos acaecidos en los partidos de izquierda. La segunda es el aumento de los conflictos armados en los otros países centroamericanos; esto provoca que se identificara al sindicalismo con el comunismo, lo que acarreó una pérdida de legitimidad para el movimiento sindical. La tercera es el aumento del número de confederaciones sindicales, pero la disminución al mismo tiempo del número de las organizaciones afiliadas a estas; esto refleja el grado de fragmentación en que se encontraba

\begin{tabular}{ll}
\hline 49 & Ibid. p. 32. \\
50 & Idem.
\end{tabular}


el movimiento sindical nacional y que impide un trabajo conjunto en beneficio de la clase trabajadora ${ }^{51}$.

La crisis vivida por los sindicatos durante este periodo fue en parte provocada por las mismas organizaciones sindicales, las cuales no saben interpretar de modo efectivo el momento histórico en que se hallan. Así, los cambios económicos, sociales y políticos que se generaban en todo el mundo $y$ en Costa Rica, no fueron ponderados adecuadamente $y$ la única opción de respuesta que se genera fue de resistencia y no de inserción y participación en estos procesos ${ }^{52}$.

Por lo tanto, podemos observar como el sindicalismo logra sobrevivir a las medidas neoliberales adoptadas a lo largo de la década de 1980, pero lejos de estar fortalecido completamente; se encuentra fragmentado, debilitado por luchas internas y sin un norte que lo guíe en la lucha social por la búsqueda de un ideal político y social que mejore las condiciones de vida de la clase trabajadora.

En la década de los 90 las tesis neoliberales se institucionalizan y el Estado empieza a generalizar la reestructuración en sus diversas instituciones a partir de la implementación de los Programas de Ajuste Estructural (PAE), cambiándose con ello el perfil de las relaciones laborales conocidas hasta entonces. Por lo que respecta al sector público, Jorge Emilio Regidor Umaña — rescata investigaciones previas - una serie de aspectos principales que se dan durante esta época de ajuste estructural:

a) Mayor intensidad del trabajo: debido a la sobrecarga de trabajo al tener que atender volúmenes crecientes de labor con menos personal en las instituciones.

b) Pérdida de derechos laborales: en general, se ha visto afectado el régimen de empleo en el sector público y uno de los

$51 \quad$ Mendoza Mora, Arnoldo. "Gobierno, empresarios $y$ sindicalismo en torno al 'fomento del sindicalismo". [Tesis para optar por el Grado de Magíster en Scientae en Sociología] Universidad de Costa Rica. Facultad de Ciencias Sociales. San José, 1994. pp. 54-55.

Rojas Morales, Víctor. Op. Cit. p. 143. mayores efectos es la pérdida de la estabilidad laboral.

c) Disminución en el pago a los trabajadores: durante todo el proceso de ajuste, la tendencia salarial para el sector ha sido regresiva.

d) Debilitamiento de las organizaciones sindicales: debido a la incapacidad para detener los cambios institucionales en marcha, así como para ser canales de conquistas laborales. También, debido a la pérdida de afiliación por desplazamientos masivos de personal y a la imposibilidad legal para entablar negociaciones formales (colectivas) con el patrono-Estado.

e) Reducción de espacios de negociación: de parte de las autoridades de Gobierno, se produce un desconocimiento de las organizaciones sindicales como legítimas representantes de los trabajadores. Así, los espacios de negociación se cierran por completo hacia 1995, habiendo comenzado el proceso desde $1979^{53}$.

Otro aspecto relevante, en cuanto al sindicalismo en el sector público, lo constituye la creación de la Ley de Sociedades Anónimas Laborales (Ley 7403 del 3 de mayo de 1994), que ha permitido la privatización parcial de servicios mediante los cuales un sector de asalariados deja de serlo para convertirse en prestadores directos del servicio a la entidad de la que provienen. Esta iniciativa ha tenido un éxito limitado — en la mayoría de los casos - ya que las nuevas sociedades creadas han carecido de una visión empresarial que les permitiera administrar adecuadamente los bienes recibidos y el desempeño de la actividad ${ }^{54}$.

53 Regidor Umaña, Jorge Emilio. Op. Cit. p. 33.

54 Aguilar Arce, Rodrigo. Notas para la construcción de una historia del sindicalismo costarricense. [Documento de trabajo inédito] 2001. En: Regidor Umaña, Jorge Emilio. "Las organizaciones sindicales centroamericanas como actores del sistema de relaciones laborales: el caso de Costa Rica". [PDF] San José: Oficina Internacional del Trabajo, 2003. p. 34 . 
En esta época, el movimiento sindical se plantea la necesidad de asumir nuevos retos, abandonando el aislamiento y el gremialismo para plantear agendas de mayor envergadura, vinculándose más con tareas de carácter nacional: en materia de seguridad social, derechos humanos, ambiente, educación, empleo, seguridad ciudadana, corrupción y en la defensa de la institucionalidad ${ }^{55}$.

Asimismo, se dan diversos intentos $y$ esfuerzos por organizar a los trabajadores en el sector privado, pero estos chocan con la actitud de los empresarios en despedir y continuar

$55 \quad$ Regidor Umaña, Jorge Emilio. Op. Cit. p. 34. sometiendo a listas negras a aquellos trabajadores que intentan formar un sindicato o afiliarse a él. Por este motivo, en lo que respecta a las actividades económicas del sector privado, la organización sindical no crece y lejos de ello, muchos de los sindicatos creados terminan por desaparecer en los años 90.

Esta situación afecta tanto a los sindicatos públicos como privados (Ver cuadro 5), ya que durante toda la década de 1990 el número de sindicatos activos disminuye todos los años, con excepción del periodo entre 1990 y 1991, cuando se da un ligero aumento — de 12 sindicatos - de este tipo de organizaciones activas.

SINDICATOS INSCRITOS ACTIVOS EN COSTA RICA (1990-1998)

\begin{tabular}{cccc}
\hline AÑO & PÚBLICOS & PRIVADOS & TOTAL \\
\hline 1990 & 143 & 277 & 420 \\
1991 & 153 & 279 & 432 \\
1992 & 156 & 267 & 423 \\
1993 & 151 & 240 & 391 \\
1994 & 149 & 238 & 387 \\
1995 & 139 & 209 & 348 \\
1996 & 134 & 185 & 319 \\
1997 & 124 & 159 & 283 \\
1998 & 134 & 149 & 283 \\
\hline
\end{tabular}

Fuente: Construcción propia, a partir de los datos del Ministerio de Trabajo y Seguridad Social encontrados en Gómez Pineda, Henry Manuel. "La función sindical en la nueva era de la globalización". [Tesis para optar por el Grado de Licenciado en Derecho] Universidad de Costa Rica. Facultad de Derecho. San José, 1999. pp. 73-77. Cuadros I, 2 y 3. 
Además, en términos generales los organismos sindicales de segundo grado tuvieron poco efecto en el país; no obstante, el ejemplo seguido por los trabajadores del ICE y el Magisterio Nacional, fue retomado por los sindicatos en las diferentes instituciones, lo que les permite crear diferentes frentes para defenderse con mayor posibilidad de éxito de la implementación de las nuevas políticas de corte neoliberal.

De esa manera, surge el Frente de Organizaciones Laborales del ICE (FOLICE), posteriormente el Frente Interno de los Trabajadores de esa misma institución (FIT) ${ }^{56}$, el Frente de Organizaciones del Ministerio de Obras Públicas y Transportes (FOMOPT), el Frente de Organizaciones Sindicales del Sector de la Salud (Fosss), el Frente de Sindicatos Universitarios (FSU), la Coordinadora Latinoamericana Sindicatos Bananeros (COLSIBA), el Frente Agrario de Organizaciones Sindicales (FAOS), integrado por sindicatos agrarios y del sector público vinculado a ese sector entre otros; con la característica de que estos frentes aglutinan a sindicatos que pertenecen a diferentes centrales sindicales $y$ a sindicatos no confederados.

El hecho de que estos "Frentes" se traten de unidades coyunturales y no orgánicas, hace que en algunas oportunidades se vean en problemas $y$ en nuevas divisiones, no constituyendo alternativas unificadoras permanentes, a pesar de haber contribuido a un despliegue organizativo y programático que se ha hecho palpable en movimientos populares significativos durante el período, como el caso del llamado Combo del ICE ${ }^{57}$.

Tiene registrada la existencia de 842 instituciones sindicales, de las cuales solo 252 se encuentran activas ${ }^{58}$. Se puede contrastar esta información con la proporcionada por el Proyecto Estado de la Nación en su Auditoría ciudadana sobre la calidad de la democracia, en el cual se establece que para el año 2000 existían 744 organizaciones sindicales en Costa Rica (Ver cuadro 6).

\section{CUADRO 6}

EVOLUCIÓN HISTÓRICA DE LA CREACIÓN DE ORGANIZACIONES SINDICALES -ACTIVAS E INACTIVASEN COSTA RICA (1978-2000)*

\begin{tabular}{ccccc}
\hline AÑO & NÚMERO & $\begin{array}{c}\text { PORCENTAJE DE } \\
\text { CRECIMIENTO DEL } \\
\text { PERÍODO }\end{array}$ & ASOCIADOS & $\begin{array}{c}\text { PORCENTAJE DE } \\
\text { CRECIMIENTO DEL } \\
\text { PERÍODO }\end{array}$ \\
\hline 1978 & 204 & - & 33827 & - \\
1980 & 280 & 37,2 & 106432 & $214,60 \%$ \\
1985 & 359 & 28,2 & 135508 & $27,60 \%$ \\
1990 & 420 & 17,0 & 154469 & $14,00 \%$ \\
1994 & 387 & $-7,9$ & 165268 & $7,00 \%$ \\
2000 & 744 & 92,2 & 186684 & $12,90 \%$ \\
\hline
\end{tabular}

\footnotetext{
*En el cuadro original se incluye además, información sobre cooperativas y asociaciones solidaristas, para la presente reproducción se obvió esta información, ya que no tiene vinculación con el propósito del presente documento.

Fuente: Proyecto Estado de la Nación en Desarrollo Humano Sostenible. Informe de la Auditoría ciudadana sobre la calidad de la democracia. 1ra. edición. San José: Proyecto Estado de la Nación, 2001. p. 311. Cuadro 10.6.

$56 \quad$ Aquí se puede observar fácilmente como continua siendo difícil lograr la integración de las organizaciones sindicales, incluso de aquellas pertenecientes a la misma institución.

\section{$57 \quad$ Idem}

58 Oficina de Organizaciones Sociales. Base de datos electrónica: listado de sindicatos. [XLS] Ministerio de Trabajo de la República de Costa Rica. Listado de sindicatos [XLS]. Proporcionado el 19 de junio, 2006 .
} 
Además las organizaciones sindicales han venido debilitándose de manera cualitativa, ya que como se menciona anteriormente, los sindicatos costarricenses han tenido que aprovechar cada vez más las coyunturas específicas para organizarse y obtener el apoyo y legitimidad necesarios para hacer valer sus demandas ante el gobierno de turno.

Como se muestra claramente en el gráfico 4, hay un significativo debilitamiento de las organizaciones sindicales durante la década de 1990, con crecimiento negativo en la mayor parte del periodo de hasta un $-12 \%$ aproximadamente. Queda claro entonces, que las políticas neoliberales y de flexibilización laboral tuvieron una fuerte repercusión negativa en la capacidad de los trabajadores de organizarse en sindicatos y disminuyeron el margen de acción de los mismos, lo cual a su vez afectó la legitimidad de estos ante la población.

\section{GRÁFICO 4 \\ CAMBIOS EN LA POBLACIÓN DE SINDICATOS DE COSTA RICA \\ (1984-1998)}

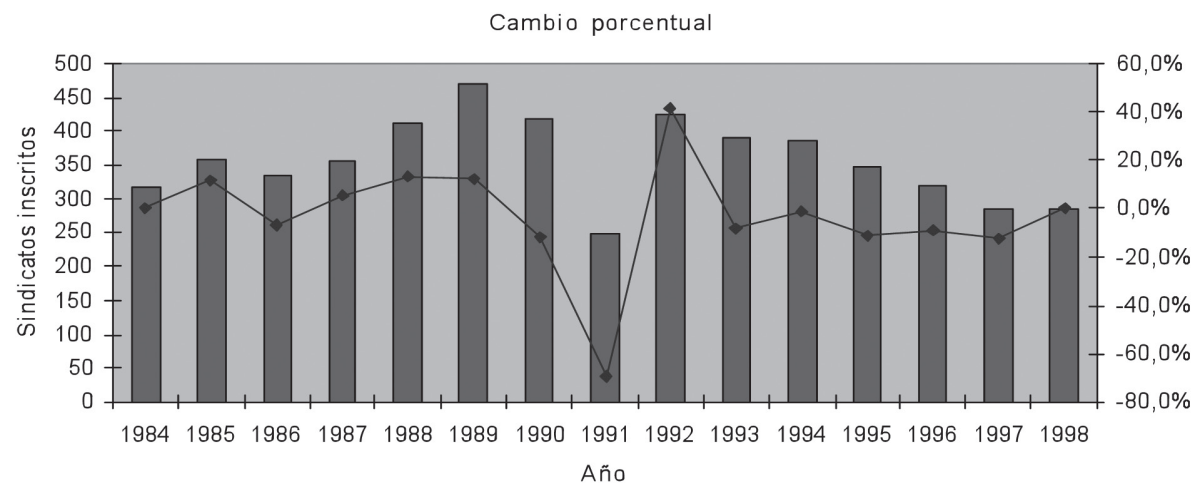

$\square$ Vigentes —Cambio porcentual

Fuente: Construcción propia, a partir de los datos encontrados en Ministerio de Trabajo y Seguridad. Base de datos electrónica: listado de sindicatos. [XLS]. Oficina de Organizaciones Sociales. Noviembre, 2009.

\section{GRÁFICO 5 \\ CAMBIOS EN LA POBLACIÓN SINDICALIZADA Y EN LA TASA DE SINDICALIZACIÓN EN COSTA RICA \\ (1983-1998)}

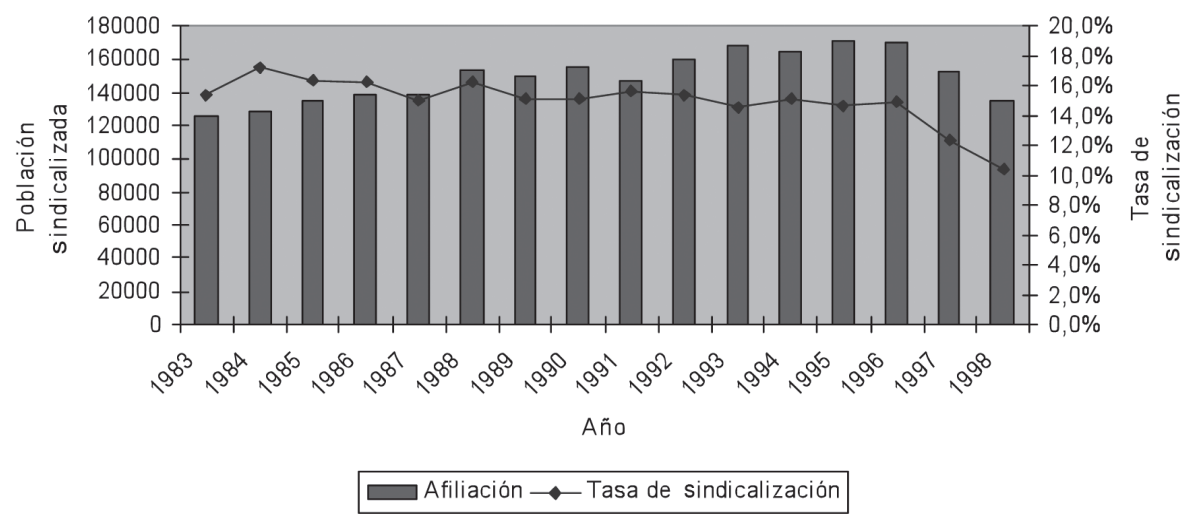

Fuente: Construcción propia, a partir de los datos encontrados en Ministerio de Trabajo y Seguridad. Base de datos electrónica: listado de sindicatos. [XLS]. Oficina de Organizaciones Sociales. Noviembre, 2009. 
Esta pérdida de legitimidad se puede apreciar en la constante disminución en la tasa de sindicalización del país entre 1984 y 1998 (ver gráfico 5), donde cae de un $18 \%$ a casi un 10\%. La disminución de la población sindicalizada incide en una disminución de la capacidad de convocatoria de los sindicatos y en una menor generación de presión social para luchar por sus objetivos.

Asimismo, el gráfico 6 muestra que a pesar de existir grandes variaciones en el número de sindicatos existentes en este periodo, esto no repercute en variaciones significativas en el descenso o aumento de las personas afiliadas a este tipo de organizaciones, esto significa que debe haber un número de sindicatos estables y constantes los cuales acaparan la mayor parte de la población sindicalizada. Desde la perspectiva de la ecología organizacional, la existencia de este tipo de organizaciones "fuertes" podría ser una de las causas que dificultan la creación y desarrollo de nuevas organizaciones.

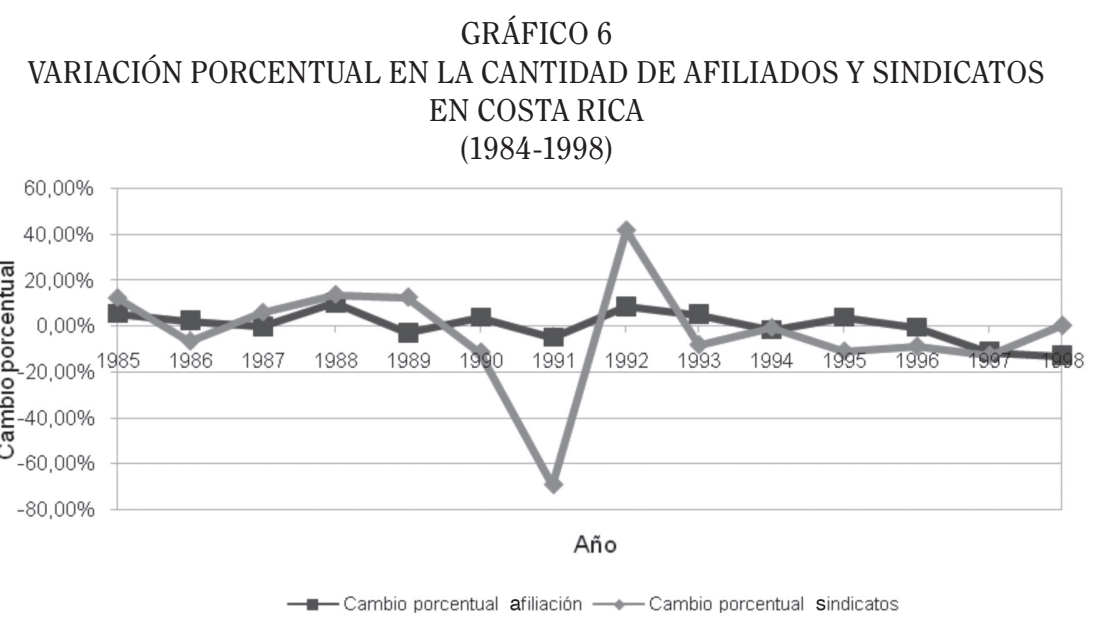

Fuente: Construcción propia, a partir de los datos encontrados en Ministerio de Trabajo y Seguridad. Base de datos electrónica: listado de sindicatos. [XLS]. Oficina de Organizaciones Sociales. Noviembre, 2009.

Esto queda apoyado al observar la correlación entre el número de sindicatos y la tasa de sindicalización durante el periodo de 1984 a 1998 (gráfico 7); ya que la correlación de
Spearman $\left(\mathrm{R}^{2}\right)$ es muy baja, apenas de $0.11, y$ el coeficiente de correlación es de 0.33 , lo cual indica la poca relación explicativa entre ambas variables.

GRÁFICO 7

CORRELACIÓN ENTRE SINDICATOS Y TASA DE SINDIZALIZACIÓN

(1984-1998)

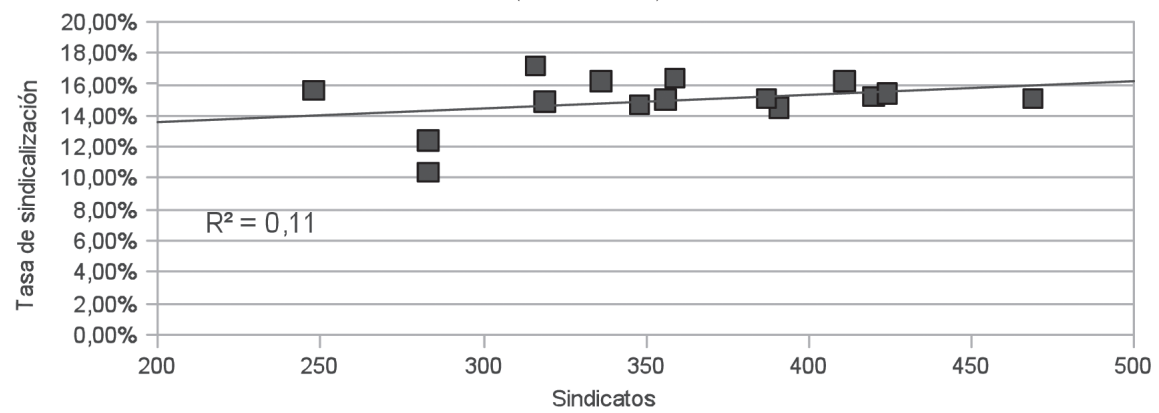

Fuente: Construcción propia, a partir de los datos encontrados en Ministerio de Trabajo y Seguridad. Base de datos electrónica: listado de sindicatos. [XLS]. Oficina de Organizaciones Sociales. Noviembre, 2009. 
Bajo la misma línea encontramos el gráfico 8, el cual si bien muestra que existe una correlación positiva entre el cambio porcentual en la afiliación sindical y el cambio porcentual en la cantidad de sindicatos activos en el país para este periodo, la correlación entre ambas variables es baja: $0.42 ; y$ el coeficiente de Spearman $\left(R^{2}\right)$ también es poco significativo: 0.11 .

\section{GRÁFICO 8 \\ CORRELACIÓN ENTRE CAMBIO PORCENTUAL EN LA AFILIACIÓN SINDICAL Y EL CAMBIO PORCENTUAL DE LA CANTIDAD DE SINDICATOS ACTIVOS EN COTA RICA}

(1984-1998)

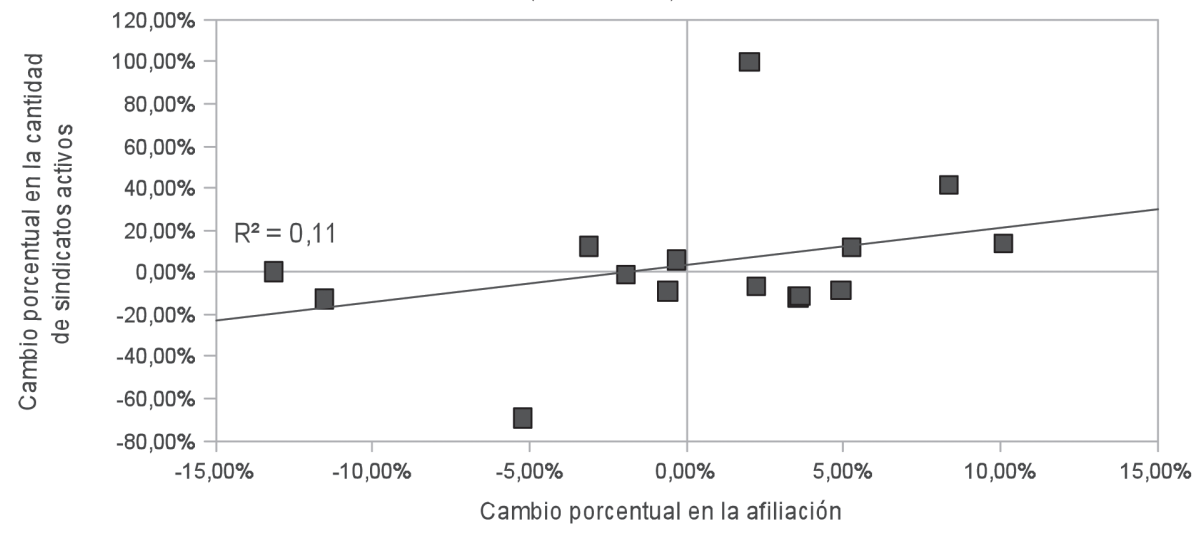

Fuente: Construcción propia, a partir de los datos encontrados en Ministerio de Trabajo y Seguridad. Base de datos electrónica: listado de sindicatos. [XLS]. Oficina de Organizaciones Sociales. Noviembre, 2009.

\section{CONCLUSIÓN}

Al analizar la historia de la población de las organizaciones sindicales en Costa Rica durante la mayor parte del siglo Xx, se encuentra que esta tiene efectivamente "sus altos y sus bajos", y su desarrollo está supeditado en gran parte al entorno político y al tipo de modelo de producción imperante en cada una de las etapas analizadas, ya que estos van a marcar la capacidad de acción que tengan este tipo de organizaciones sociales.

Para la última etapa, que abarca las décadas finales del siglo xx, llama la atención que hay poca relación entre el número de afiliados $y$ el crecimiento de la población de organizaciones sindicales, esto muestra que existe una población bastante estable de sindicatos que logra subsistir a pesar de la constante disminución en la tasa de sindicalización en Costa Rica.

Asimismo, se denota un gran proceso de fragmentación y falta de cohesión en el sindicalismo costarricense a partir de 1962, lo cual ha repercutido negativamente en la capacidad de representación de este tipo de organizaciones de las demandas de los trabajadores, así como en la disminución de su capacidad de impulsar un proyecto político alternativo.

\section{FUENTES DE INFORMACIÓN CONSULTADAS}

Aguilar Arce, Rodrigo. Actualidad del movimiento sindical en Costa Rica. 1. ${ }^{a}$ edición. San José: Sindicatos de Educadores Costarricenses-Fundación Friedrich Eberth, FES. 1993.

Aguilar Hernández, María de los Ángeles. "Clase trabajadora y organización sindical en Costa Rica (1948-1971)". [Tesis para optar por el Grado de Magíster en Scientae en Sociología]. Universidad de Costa Rica. San José. 1987.

Aguilar Hernández, María de los Ángeles. Clase trabajadora y organización sindical en 
Costa Rica 1943-1971. 1. a edición. San José: Editorial PORVENIR-FLACSO-ICES, 1989.

Bittel, L. R. y Ramsey, J. E. Enciclopedia del Management 3. 1. ${ }^{a}$ edición. Madrid: Editorial McGraw-Hill/Cetrum, 1988.

Córdoba Arancibia, Juan. "La integración centroamericana y los trabajadores". Portella de Castro, María Silvia y Wachendorfer, Achim (coordinadores). Sindicalismo y globalización: la dolorosa inserción en un mundo incierto. $1 .^{\mathrm{a}}$ edición. Caracas: Editorial Nueva Sociedad, 1998.

De la Cruz, Vladimir. "Características y rasgos históricos del movimiento sindical en Costa Rica”. Nowalski, Jorge (editor). El sindicalismo frente al cambio: entre la pasividad y el protagonismo. 1. ${ }^{\text {a }}$ edición. San José: Editorial DEI, 1997.

Gómez Pineda, Henry Manuel. "La función sindical en la nueva era de la globalización". [Tesis para optar por el Grado de Licenciado en Derecho]. Universidad de Costa Rica. Facultad de Derecho. San José. 1999.

Mendoza Mora, Arnoldo. "Gobierno, empresarios y sindicalismo en torno al "fomento del sindicalismo". [Tesis para optar por el Grado de Magíster en Scientae en Sociología]. Universidad de Costa Rica. Facultad de Ciencias Sociales. San José. 1994.

Ministerio de Economía, Industria y Comercio. Anuario Estadístico de Costa Rica (19831987). Área de Estadísticas y Censos. San José. 1997.

Ministerio de Economía, Industria y Comercio. Anuario Estadístico de Costa Rica (19881992). Área de Estadísticas y Censos. San José. 1998.
Ministerio de Trabajo y Seguridad. Base de datos electrónica: listado de sindicatos. [XLs]. Oficina de Organizaciones Sociales. Proporcionado el 19 de junio, 2006.

Molina Jiménez, Iván. Anticomunismo reformista: competencia electoral y cuestión social en Costa Rica (19311948). 1. a edición. San José: Editorial Costa Rica, 2009.

Proyecto Estado de la Nación en Desarrollo Humano Sostenible. Informe de la auditoría ciudadana sobre la calidad de la democracia. 1. edición. San José: Proyecto Estado de la Nación, 2001.

Regidor Umaña, Jorge Emilio. Las organizaciones sindicales centroamericanas como actores del sistema de relaciones laborales: el caso de Costa Rica. [PDF] San José: Oficina Internacional del Trabajo, 2003.

Rojas Bolaños, Manuel. "El desarrollo del Movimiento Obrero en Costa Rica; un intento de periodización". Abarca, Carlos A. y otros. Desarrollo del movimiento sindical en Costa Rica. 1. a edición. San José: Editorial Universidad de Costa Rica, 1981.

Rojas Morales, Víctor. "Crisis y movimiento sindical en Costa Rica (1980-1985)". [Tesis para optar por el Grado de Licenciado en Historia]. Universidad de Costa Rica. Facultad de Ciencias Sociales. San José. 1999.

Romano Schutte, Giorgio. "El sindicalismo bananero en América Central en busca de nuevos caminos". Portella de Castro, María Silvia y Wachendorfer, Achim (coordinadores). Sindicalismo $y$ globalización: la dolorosa inserción en un mundo incierto. 1. ${ }^{\text {a }}$ edición. Caracas: Editorial Nueva Sociedad, 1998. 
